\title{
EMISSÕES DE GASES DE EFEITO ESTUFA POR RESERVATÓRIOS DE HIDRELÉTRICAS
}

\author{
Marco Aurélio dos Santos ${ }^{1}$, Luiz Pinguelli Rosa ${ }^{1}$, Bohdan Matvienko², Ednaldo Oliveira dos Santos ${ }^{3}$, Carlos \\ Henrique Eça D'Almeida Rocha ${ }^{3}$,Elizabeth Sikar ${ }^{2}$, Marcelo Bento Silva ${ }^{2}$ \& Ayr Manoel P. B. Junior ${ }^{4}$
}

${ }^{1}$ Programa de Planejamento Energético, COPPE/UFRJ, Centro de Tecnologia, Bloco C- Sala 211. Caixa Postal 68565. Rio de Janeiro, Rio de Janeiro, Brasil. CEP: 21941972.

${ }^{2}$ Construmaq São Carlos Ltda., Rua Sebastião de Moraes, 610. Jardim Santa Felícia. São Carlos, São Paulo, Brasil. CEP: 13562-040.

${ }^{3}$ Instituto Virtual Internacional de Mudanças Globais (IVIG)/COPPE/UFRJ, Centro de Tecnologia, Bloco I-2000, sala 129. Rio de Janeiro, Rio de Janeiro, Brasil. CEP: 21945-970.

4 Programa de Engenharia Química. COPPE/UFRJ. Instituto Alberto Luiz Coimbra de Pós-Graduação e Pesquisa de Engenharia,. Centro de tecnologia, B1 G, sala 128. - Rio de Janeiro, RJ - Brasil CEP: 21945-970.

E-mails: aurelio@ppe.ufrj.br, pinguelli@ppe.ufrj.br, b.matvienko@terra.com.br, ednaldo@ppe.ufrj.br, carlos.rocha@coc.ufrj.br, elizabeth@linkway. com.br, bentoms20@hotmail.com, ayr@peq.coppe.ufrj.br.

\section{RESUMO}

Durante a década de 90 surgiram intensas especulações a respeito de que reservatórios de hidrelétricas poderiam estar contribuindo para a intensificação do efeito estufa através da emissão de Gases de Efeito Estufa $(G E E)$. Muita polêmica tem sido estabelecida recentemente a partir de estudos realizados nos reservatórios amazônicos, especialmente a partir de estudos teóricos e baseados em extrapolações desprovidas de critérios científicos estabelecidos. Uma das questões mais polêmicas é a estimativa de emissão de gases à jusante de represas, logo após a passagem da água pelas turbinas, em particular do metano $\left(\mathrm{CH}_{4}\right)$ cujas concentrações são mais elevadas em maiores profundidades. Um dos problemas é que a concentração de $\mathrm{CH}_{4}$ a ser utilizada nos cálculos de fluxo ebulitivo deveria ser a concentração média deste gás na faixa de captação de água e não a concentração deste gás na profundidade maior, como tem sido usado. A intensidade da emissão de GEE não é invariante no tempo, havendo flutuações em períodos de duração irregular. Estas flutuações são influenciadas por muitos fatores, como temperatura, regime de ventos, exposição ao sol, parâmetros físicos, químicos e biológicos da água. Existem dificuldades para se estabelecer uma extrapolação que realmente represente a heterogeneidade espacial dos reservatórios e que possa captar a variação temporal dos fluxos. Estudos adicionais são indispensáveis para reduzir as dúvidas a respeito da emissão de GEE pelos reservatórios de hidrelétricas. A compreensão das diferentes formas de fluxo de carbono, em diferentes escalas espaciais (nível do reservatório, nível da coluna d'água) e temporais (antes e depois da inundação) é indispensável para compreender a real contribuição do reservatório na emissão de GEE. Muitos ambientes naturais emitem $\mathrm{CH}_{4}$, especialmente pântanos e outras áreas úmidas ou habitats de florestas em climas tropicais. Estas emissões devem ser consideradas e descontadas em cálculos de emissões de $\mathrm{CH}_{4}$ posteriores a inundação do reservatório neste tipo de ambiente. Este método garante que os dados obtidos após a inundação representem realmente o aumento na emissão de $\mathrm{CH}_{4}$ provocado pela inundação da área pela represa. A emissão de $\mathrm{CH}_{4}$ pelas hidrelétricas é sempre desfavorável para a hidroeletricidade, pois mesmo que o carbono origine-se de fontes naturais, ele se torna um gás de maior Potencial de Aquecimento Global (Global Warming Potential - GWP) no computo final. Já a emissão de $\mathrm{CO}_{2}$ em parte pode ser originada da atmosfera e ser incorporada ao sistema do reservatório pela ciclagem natural do carbono em ciclo curto de tempo.

Palavras-chave: Hidroeletricidade, carbono, metano, dióxido de carbono, emissão de gases

\begin{abstract}
GREENHOUSE GAS EMISSIONS OF DIFFERENT BRAZILIAN HYDROELECTRIC DAMS. Over the 90s surged a growing concern about the participation of hydroelectric dams in the global warming through considerable emission of greenhouse gases. Recently, the results of analysis of some hydroelectric dams in the Amazon have become a matter of controversy, since some of them were based and obtained by poorly reliable scientific methods. One of the most controversial aspects are the greenhouse gases emission by the
\end{abstract}


downstream face of the dams - i.e. just after the turbines - especially of methane, which is found in greater concentrations at greater depths. It has been proposed that the gas concentration that should be considered when calculating the ebullition flux should be that of the capitation area, instead of the usually employed methane concentration at greater depths. The greenhouse gas emissions of hydroelectric dams is not constant, and proved to vary in an irregular basis that depends on many factors, including temperature, exposure to sunlight, and water physicochemical and biological traits. There are no established models for the spatial and temporal variations of greenhouse gas emissions by hydroelectric dams, which heavily depend on results of additional controlled studies. There is a lack of data on the carbon cycle conditions in different situations (according with water level, water column position, before and after impoundment, etc). For instance, different types of environments naturally generate methane (swamps, flooded forests). These emissions ought to be discounted when calculating methane emissions after water impoundment within such regions, thus ensuring the obtained figures really reflect the increase in methane emissions after the dam was constructed. Carbon dioxide emissions could be incorporated into the hydroelectric dam system through natural cycling within a short time span.

Keywords: Hydroelectricity, carbon, methane, carbon dioxide, gas emission

\section{HISTÓRICO}

Durante a década de 90 as hidrelétricas passaram a ser alvo de intensas especulações a respeito de que seus reservatórios estariam contribuindo para a intensificação do efeito estufa, através da liberação de gases como produto da decomposição de material orgânico em sua bacia de acumulação. Estes gases produzidos seriam: o dióxido de carbono $\left(\mathrm{CO}_{2}\right)$, o metano $\left(\mathrm{CH}_{4}\right)$ e o óxido nitroso $\left(\mathrm{N}_{2} \mathrm{O}\right)$, gases de origem biogênica que comprovadamente interagem com a radiação infravermelha na atmosfera causando intensificação do efeito estufa natural (IPCC 2001). Diante destas críticas, medidas de fluxos de gases foram realizadas em 1993 nas hidrelétricas de Balbina, Tucuruí e Samuel, encontrando forte presença de $\mathrm{CH}_{4}$ emitido em bolhas, sendo esta mais elevada nos reservatórios mais recentes (Rosa et al. 1996).

Nesta mesma época, foi realizada uma comparação das emissões de futuras hidrelétricas com as de termelétricas que poderiam ser construídas em lugar das primeiras (Rosa et al. 1996). O método baseou-se em dados sobre densidade de biomassa e em características técnicas das usinas. Assumiu-se que parte da biomassa submersa pelo enchimento do reservatório se decompõe em tempo relativamente curto, decaindo exponencialmente em poucos anos; enquanto troncos e galhos grossos permanecem decompondo-se muito lentamente, somando estas emissões àquelas que o lago terá continuamente por toda a sua vida (Rosa et al. 1996). O principal problema encontrado ao se comparar os efeitos das emissões das hidrelétricas (emissões variam no tempo), com as de termelétricas (emitem gases de combustão a taxa quase constante por toda sua vida útil) é comparar emissões feitas com intensidade variável em tempos diferentes.

A situação mais extrema na emissão de gases de efeito estufa (GEE) foi registrada em Balbina, onde as emissões calculadas foram mais altas do que as de uma termelétrica a carvão que gera a mesma energia. A usina de Tucuruí emitia bem menos gases do que uma termelétrica equivalente, mesmo a gás natural com ciclo combinado (Rosa et al. 1996, Rosa et al. 1997). Pesquisadores do INPA (Instituto de Pesquisas da Amazônia), com base em estimativa das emissões de Balbina, discordaram dos resultados apresentados (Fearnside 1995, Fearnside 1996)

Outro estudo foi realizado para Furnas Centrais Elétricas e Serra da Mesa Energia S.A. em 1997, com o objetivo de medir as emissões de $\mathrm{CO}_{2}$ e $\mathrm{CH}_{4}$ no reservatório de Serra da Mesa, recém fechado na época. Estudo semelhante foi empregado no lago de Itaipu em 1998, a partir de uma demanda da Itaipu Binacional visando determinar suas emissões brutas de GEE. Ainda em 1998, pesquisadores da Coordenação dos Programas de Pós-Graduação em Engenharia da Universidade Federal do Rio de Janeiro (COPPE/UFRJ), com o apoio da Eletrobrás e do Ministério de Ciência e Tecnologia (MCT), iniciou um grande estudo envolvendo sete diferentes reservatórios, distribuídos ao longo de diferentes biomas e latitudes no país (Figura 1). Além destes reservatórios estudados também foram utilizados os dados de Serra da Mesa e Itaipu.

Durante o desenvolvimento destes trabalhos, ante- 
riormente citados, muitas questões foram levantadas; entre elas: a extrapolação de um dado para outra área do reservatório e de um reservatório para outro, o comportamento das emissões no tempo, as emissões líquidas versus emissões brutas, a origem da matéria orgânica (autóctone ou alóctone), dentre outras.

Uma destas questões (comportamento das emissões ao longo do tempo) motivou a continuidade dos estudos, a partir de um convênio com a Agência Nacional de Energia Elétrica (ANEEL) em 2001. Este estudo procurou investigar com mais detalhes as emissões de $\mathrm{CO}_{2}$ e $\mathrm{CH}_{4}$ em dois reservatórios já estudados anteriormente (Xingó e Miranda) de forma a examinar o comportamento e a dinâmica destas emissões em diversas campanhas de campo no decorrer de um ano de trabalho. Em parceria com outros grupos de pesquisa, finalizamos este ano um estudo de balanço de massa de carbono em oito reservatórios de Furnas Centrais Elétricas S.A (2003-2008) durante três períodos hidrológicos distintos.

Pretendia-se ainda avaliar as emissões naturais anteriores à construção da barragem, para que estes resultados pudessem ser reduzidos das emissões futuras atribuídas ao reservatório. Desta maneira pretende-se obter as emissões líquidas de gases gerados a partir da construção da barragem. A literatura científica sobre o assunto denomina as emissões sem este desconto como "emissões brutas" e com este desconto como "emissões líquidas". Estudamos a emissão de GEE de áreas naturais que seriam inundadas para a construção do Complexo Hidroelétrico (CHE) Belo Monte de 2003 a 2004.

\section{PROCESSOS DE GERAÇÃO E MECANISMOS DE TRANSPORTE DE GASES DE EFEITO ESTUFA (GEE) EM RESERVATÓRIOS}

$\mathrm{O} \mathrm{CO}_{2}$ e o $\mathrm{CH}_{4}$ são formados durante a decomposição de matéria orgânica por via aeróbica (respiração) e anaeróbica (metanogênese). $\mathrm{O} \mathrm{N}_{2} \mathrm{O}$ é um produto intermediário dos processos de nitrificação e desnitrificação. Em reservatórios, a fonte de matéria orgânica pode ser a biomassa inundada pré-existente, o carbono orgânico dissolvido e particulado trazido da área terrestre circunvizinha (escoamento superficial, água subterrânea, chuva) e a biomassa gerada dentro do reservatório (produção primária). Na camada óxica de água, o $\mathrm{CO}_{2}$ é produzido por decomposição aeróbica de carbono orgânico dissolvido e particulado e da oxidação biológica do $\mathrm{CH}_{4}$ gerado nas mais baixas camadas de água. Nas camadas anóxicas da coluna d'água ou do sedimento ocorre a decomposição anaeróbica da matéria orgânica que pode resultar em $\mathrm{CH}_{4}$ e $\mathrm{CO}_{2}$ através da metanogênese.

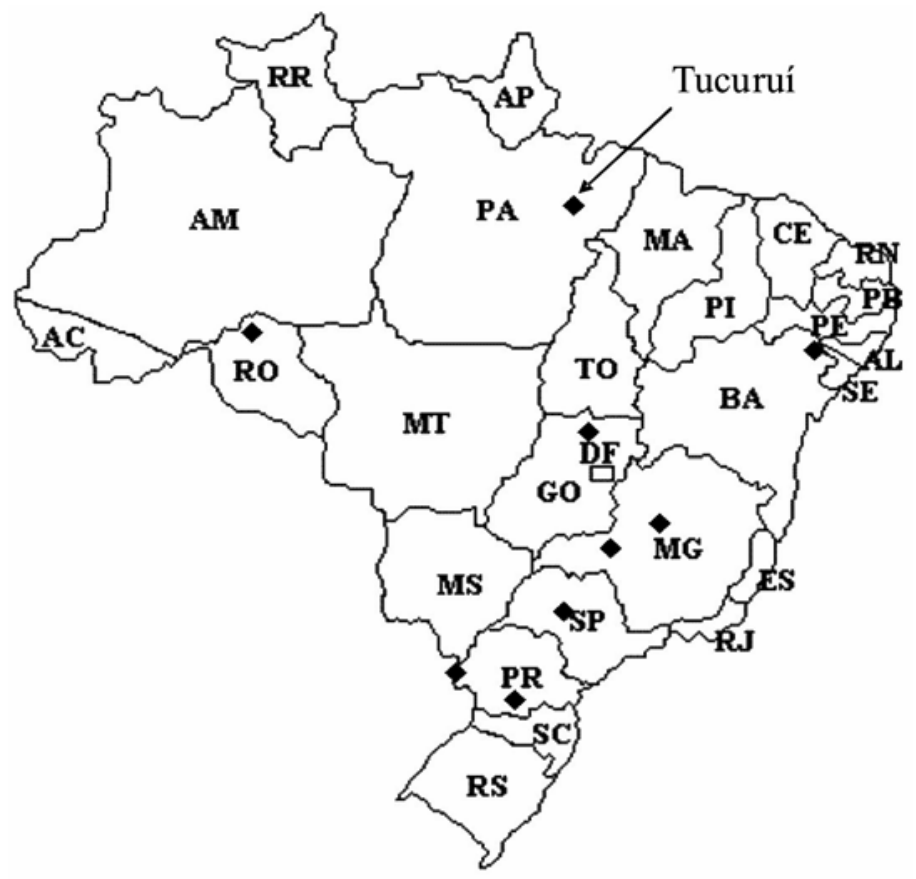

Figura1. Localização Geográfica dos reservatórios estudados. Figure 1. Geographic location of the studied hydroelectric reservoirs. 
Se o estoque de biomassa inicial, o modo de decomposição e as trajetórias do carbono forem bem compreendidos, os fluxos de gases podem ser calculados através de modelos de conservação de massa. No entanto, atualmente, resultados confiáveis só podem ser obtidos através de medições de campo de troca de gás na interface ar-água.

Nem todo $\mathrm{o}_{4} \mathrm{CH}_{4}$ é emitido por bolhas. Parte do metano produzido no ambiente difunde-se da coluna d'água até a superfície através do transporte vertical passivo (difusão molecular) e pelo transporte ativo das correntes de convecção da água que se formam a partir da diferença térmica entre os estratos ali formados. Bactérias metanotróficas presentes em suspensão na coluna d'água podem oxidar $\mathrm{O}_{\mathrm{CH}_{4}}$ e produzir $\mathrm{CO}_{2}$ e compostos orgânicos. Desta forma a camada oxigenada de água onde ficam as bactérias metanotróficas atuariam como um sumidouro de $\mathrm{CH}_{4}$.

\section{MÉTODOS DE AMOSTRAGEM DE GASES}

Emissões de metano $\left(\mathrm{CH}_{4}\right)$ e dióxido de carbono $\left(\mathrm{CO}_{2}\right)$ são determinadas através de medidas de taxas de emissão de bolhas que emanam do fundo do lago por efeito de sua saturação e que são transportados verticalmente no gradiente do lago por difusão. Para determinação qualitativa e quantitativa das taxas de emissão de $\mathrm{CH}_{4}$ e $\mathrm{CO}_{2}$ em mg.m ${ }^{-2} \cdot \mathrm{d}^{-1}$ são realizadas as seguintes medidas:

a) taxa de emissão de gás na forma de bolhas, usando-se funis para capturá-las após a sua liberação espontânea, e

b) taxa de gás emitido por difusão (que mais corretamente deveria ser chamado de emanação), usando-se "câmaras de difusão".

Estas câmaras de difusão são dispositivos que se assemelham a pequenos copos invertidos com volume total de $75 \mathrm{ml}$ e capazes de conter submersa uma "bolha" de ar atmosférico a pequena profundidade (cerca de $20 \mathrm{~cm}$ abaixo da superfície) com área de contato de $0,22 \mathrm{dm}^{2}$, através da qual se dá a troca gasosa - a emanação, aqui chamada de difusão. Após contato de 0, 3, 6 e 12 minutos, as amostras são levadas ao laboratório e a variação da concentração de cada gás é estimada por cromatografia gasosa, permitindo o cálculo da taxa de emissão ou absorção, conforme o caso.
As amostras de bolhas são coletadas empregando-se um conjunto de 16 funis coletores de bolhas (cones de napa sintética, com armação de alumínio, diâmetro de $1 \mathrm{~m}$ e acoplados a garrafas coletoras de gases). Estes funis são dispostos de sub-superfície (em torno de $1 \mathrm{~m}$ de profundidade), acopladas a garrafas plásticas que servem como bóias e ancorados por poitas de pedras, com cerca de $10 \mathrm{~kg}$ cada uma.

A escolha do sítio de amostragem e a seqüência dos funis são determinadas por parâmetros como: densidade da vegetação alagada, tipo de ambiente do reservatório (baías, braços abrigados, calha principal do reservatório, entre outros) e profundidade, presença de vegetação semi-afogada. Os funis permanecem por 24 horas no local e, durante este período, as bolhas que emanam do fundo são capturadas. Posteriormente, as garrafas coletoras são fechadas hermeticamente dentro da água e recolhidas para posterior análise em laboratório.

Para obter taxas de emissão por bolhas são usados os valores medidos para as diversas faixas de profundidade e são estabelecidas funções matemáticas aproximadas que descrevem as taxas de emissão em função da profundidade. Uma das funções é uma reta e as outras são exponenciais.

As taxas são expressas em $\mathrm{mg}$ de gás $\mathrm{m}^{-2} \cdot \mathrm{d}^{-1}$. Multiplicando-se os pares correspondentes de área e taxa se obtém a massa total de gás emitido para cada faixa de profundidade da represa. A soma dos valores obtidos representa a massa emitida pela represa toda. A partir das massas totais emitidas, são calculadas para cada gás, taxas médias para a represa, expressas em kg.k $\mathrm{k}^{-2} \cdot \mathrm{d}^{-1}$.

\section{CONCENTRAÇÕES DE METANO À JUSANTE DA BARRAGEM}

Muita polêmica tem sido estabelecida recentemente a partir de estudos realizados em reservatórios amazônicos, especialmente a partir de estudos teóricos e baseados em extrapolações desprovidas de critérios científicos estabelecidos. Estes estudos têm forte viés contra qualquer tipo de aproveitamento hidrelétrico na Amazônia e colocam em dúvida a viabilidade destes empreendimentos no que se refere às emissões de gases de efeito estufa e foram realizados para as hidrelétricas de Tucuruí, Samuel e Balbina (Fearnside 1995, Fearnside 1996, Kemenes et al. 2007). 
Este último caso, da hidrelétrica de Balbina, já fora estudado anteriormente e havia sido demonstrado que as emissões brutas de Balbina superam as de termelétricas a carvão que produzem energia equivalente (Santos 2000, Rosa et al. 2004). A comparação é muito sensível à densidade de potência de Balbina, cerca de $0,1 \mathrm{~W} / \mathrm{m}^{2}$, valor que chega a ser até 500 vezes menor do que de outras hidrelétricas brasileiras. Fluxos de bolhas $\left(\mathrm{CH}_{4}\right.$ e $\left.\mathrm{CO}_{2}\right)$ na superfície do reservatório desta hidrelétrica foram medidos e, a partir de resultados obtidos em dois períodos distintos em 1993, estimou-se uma contribuição anual de cerca 28.000t de carbono (C) contidos no $\mathrm{CH}_{4}$. Estes resultados já demonstravam que Balbina representava um dos piores casos de emissão de gases de efeito estufa, de todo o parque hidrelétrico brasileiro.

O valor encontrado por Kemenes (2006) para emissão de $\mathrm{CH}_{4}$ pela superfície do reservatório de Balbina, 34.000t, diferiu em cerca de $20 \%$ do valor encontrado nos trabalhos publicados por Rosa et al. (1996), sendo, portanto, compatível em ordem de magnitude.

Um das questões mais polêmicas é a estimativa de emissão de gases à jusante de represas, logo após a passagem da água pelas turbinas, em particular do $\mathrm{CH}_{4}$ cujas concentrações são mais elevadas em maiores profundidades. Esta concentração elevada de $\mathrm{CH}_{4}$ no fundo do reservatório de Tucurui foi objeto de publicação de nosso grupo de pesquisa citada Climatic Change (Fearnside 2004) e usada para estimar a emissão à jusante, chegando a um valor muito elevado, do qual discordamos (Rosa et al. 2006). $\mathrm{Na}$ conclusão do trabalho publicado na Geophysical Research Letters (Kemenes et al. 2007), os autores superestimam o valor de emissão de $\mathrm{CH}_{4}$ à jusante (fluxo ebulitivo nas turbinas e fluxo difusivo no rio Uatumã após a barragem) do reservatório da hidrelétrica de Balbina como sendo 39.000t de carbono por ano (34.000t e 5.000t respectivamente).

O resultado do fluxo ebulitivo (Kemenes et al. 2007) baseia-se em uma regressão linear entre a vazão da água turbinada e o chamado fluxo ebulitivo na saída das turbinas, que é obtido pela diferença de concentração do gás $\mathrm{CH}_{4}$ na profundidade da entrada da tomada d'água da turbina (30m) e a concentração do mesmo gás $50 \mathrm{~m}$ após a saída de água da turbina (jusante).

Para se obter o fluxo ebulitivo pela água turbinada, os autores baseiam-se na conservação de massa, esta- belecendo através de medidas de concentração de $\mathrm{CH}_{4}$ à montante e à jusante da barragem a diferença entre a massa de gás que entra e a que é medida $50 \mathrm{~m}$ após as turbinas, multiplicando essa diferença pela vazão turbinada, de acordo com dados da Eletronorte:

$$
\Phi=Q\left(\rho_{2}-\rho_{1}\right)
$$

(Onde: $\Phi$ = fluxo ebulitivo; $\mathrm{Q}$ = vazão da turbina; $\rho_{2}=$ concentração de $\mathrm{CH}_{4} 50 \mathrm{~m}$ à jusante da barragem e $\rho_{1}=$ concentração de $\mathrm{CH}_{4}$ na altura da tomada d'água (à montante).

Concordamos com esta abordagem, com a ressalva de que Kemenes et al. (2007) cometeram um equívoco na questão da profundidade da tomada d'água à montante. Tanto neste artigo, quanto na tese de doutorado de Kemenes (2006) foi utilizada a profundidade de $30 \mathrm{~m}$ como sendo representativa para o cálculo da vazão de $\mathrm{CH}_{4}$.

Como citado por Kemenes (2006) em sua tese de doutorado, a profundidade de $30 \mathrm{~m}$ contém uma maior concentração de $\mathrm{CH}_{4}$ na água, tendo sido realizada a coleta a esta profundidade.

“... é conhecido que condições ambientais em águas profundas de lagos tropicais favorecem a metanogênese (Richey et al. 1988) e que as concentrações de $\mathrm{CH}_{4}$ dissolvido aumentam significativamente com a profundidade em reservatórios tropicais (Galy-Lacaux et $\underline{\text { al. }}$. 1999)... A água à montante da barragem foi coletada numa profundidade de $30 \mathrm{~m}$ com uma garrafa de RUTNER".

Revendo os dados do projeto de Balbina, observamos que a tomada d'água vai de cerca de $30 \mathrm{~m}$ (limite inferior) até cerca de $15 \mathrm{~m}$ (limite superior) de profundidade, com uma amplitude aproximada de $15 \mathrm{~m}$ (Figura 2). Portanto, a concentração de $\mathrm{CH}_{4}$ a ser utilizada nos cálculos de fluxo ebulitivo deveria ser a concentração média de $\mathrm{CH}_{4}$ nesta faixa de profundidade e não a $30 \mathrm{~m}$ como utilizado pelos autores.

Kemenes et al. (2007) apresentam resultados de concentração média de $\mathrm{CH}_{4}$ em diversas profundidades no reservatório. Estes resultados deram origem a dois perfis de concentração média de $\mathrm{CH}_{4}$ e $\mathrm{CO}_{2}$. De acordo com os perfis, a concentração média de $\mathrm{CH}_{4}$ na água varia de valores próximos a zero (a $15 \mathrm{~m}$ de 


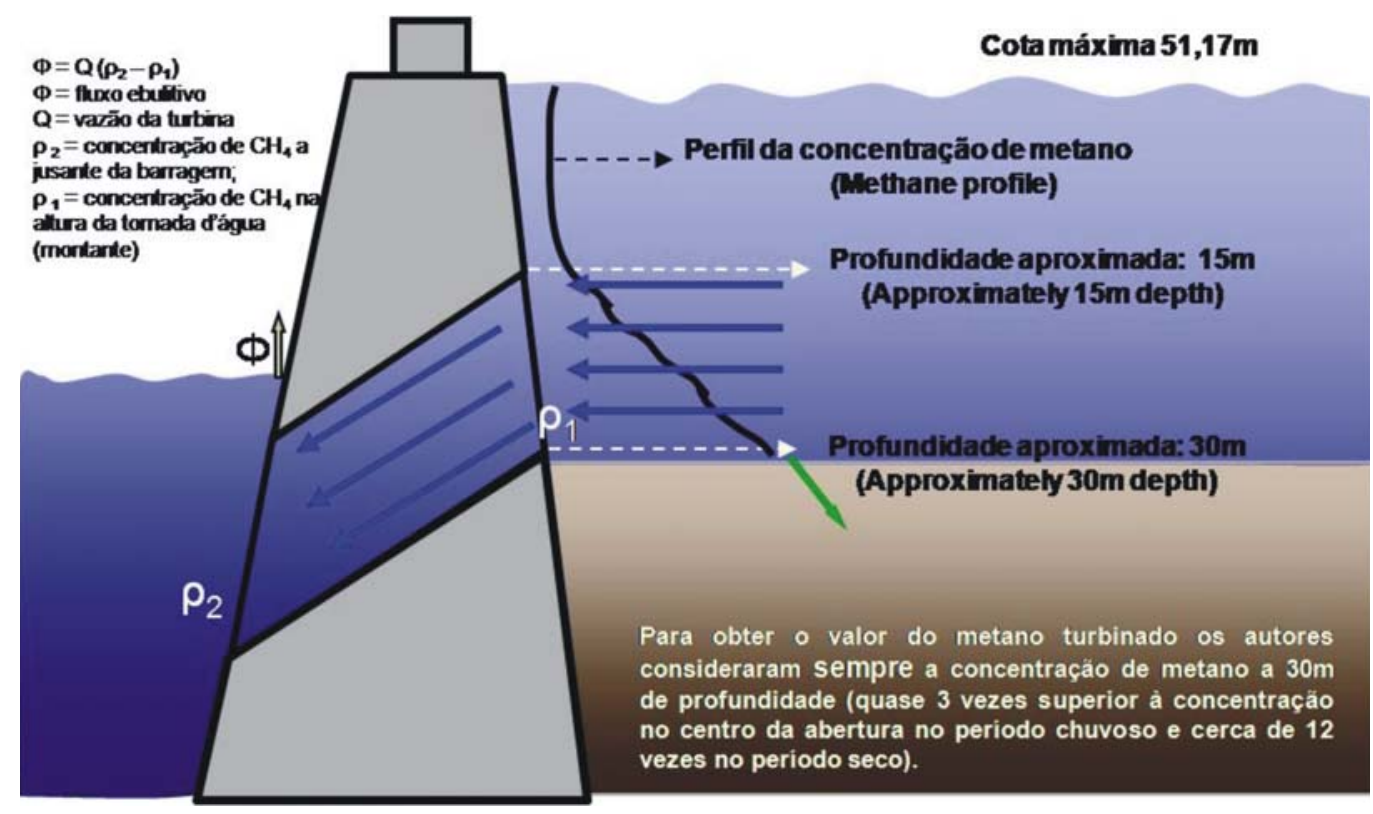

Figura 2. Esquema empregado no cálculo da emissão de metano após a passagem nas turbinas em Balbina.

Figure 2. Detailed scheme used to calculate methane emission from the passage through the turbines in the hydroelectric power station of Balbina. To calculate the amount of turbinated methane, only methane concentrations at $30 \mathrm{~m}$ depth were considered, which are almost $3 / 12$ times higher than the

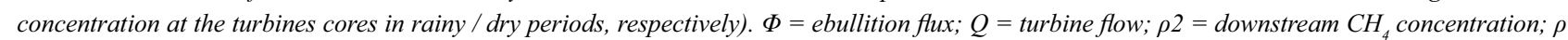
$1=$ upstream $\mathrm{CH}_{4}$ concentration.

profundidade), até $245 \mu \mathrm{mol}$ de $\mathrm{CH}_{4}$ (a $\left.30 \mathrm{~m}\right)$, durante o período seco e de $5 \mu \mathrm{mol}$ (a $15 \mathrm{~m}$ ) até $125 \mu \mathrm{mol}$ (a $30 \mathrm{~m}$ ) durante o período chuvoso (Figura 2).

Um cálculo simples com base nos perfis da Figura 3 dá a média da concentração de $\mathrm{CH}_{4}$ na água nas profundidades entre $15 \mathrm{~m}$ e $30 \mathrm{~m}$ durante o período seco igual a cerca de $40 \%$ do valor a $30 \mathrm{~m}$ e, durante o período chuvoso, igual a aproximadamente $30 \%$ do valor a $30 \mathrm{~m}$.

Os autores, entretanto, usaram nos seus cálculos a concentração medida $\rho_{1}$ a $30 \mathrm{~m}$ de profundidade junto à tomada de água. Os percentuais acima, se fossem aplicáveis, levariam a uma concentração média anual de $\mathrm{CH}_{4} \rho_{1}$ na tomada de água com valor pouco acima da concentração média $\rho_{2}$ registrada pelos autores à jusante, $50 \mathrm{~m}$ após a barragem (Figura 4), que é da ordem de $50 \%$ da concentração $\rho_{1}$ medida por eles, incluindo ambos os períodos seco e chuvoso.

Portanto:

a. Como o fluxo ebulitivo no turbinamento não é medido diretamente, mas sim calculado por subtração de duas grandezas medidas com erros experimentais que se superpõem o resultado obtido pelos autores é muito sensível, exigindo uma análise estatística mais rigorosa.

b. Mesmo ponderando com as vazões diferentes no período seco e no período chuvoso, os percentuais acima não são aplicáveis para estimar o valor do fluxo ebulitivo na passagem da água pelas turbinas, pois se referem a valores médios e, para isso, precisaríamos dos valores das concentrações de $\mathrm{CH} 4, \rho_{1}$ e $\rho_{2}$, medidas, para cada valor da vazão.

c. Os valores dessas medidas não se encontram nos artigos e nem na tese, ao menos na versão de que dispomos, da qual constam apenas os valores do fluxo $\Phi$ $=\mathrm{Q}\left(\rho_{2}-\rho_{1}\right)$ calculados com base nos valores medidos de $\rho_{1}$ e $\rho_{2}$ para um conjunto de valores da vazão $Q$.

\section{VARIABILIDADE TEMPORAL DAS EMISSÕES DO ESPELHO D'ÁGUA}

A intensidade das emissões não é invariante no tempo. Existem flutuações com períodos de duração irregular. Estas flutuações são influenciadas por uma série de fatores, principalmente temperatura, regime de ventos, exposição ao sol, parâmetros físicos, químicos e biológicos da água. Por exemplo, se colocarmos conjuntos de funis e câmaras em diferentes posições em diferentes períodos de tempo teremos variações significativas dos fluxos de gases.

Existem dificuldades para se estabelecer uma extrapolação que realmente represente a heterogeneidade espacial dos reservatórios e que possa captar a variação temporal dos fluxos. De acordo com nossa experiência empírica, existem duas fases distintas no que diz respeito às emissões de gases nos reservatórios 

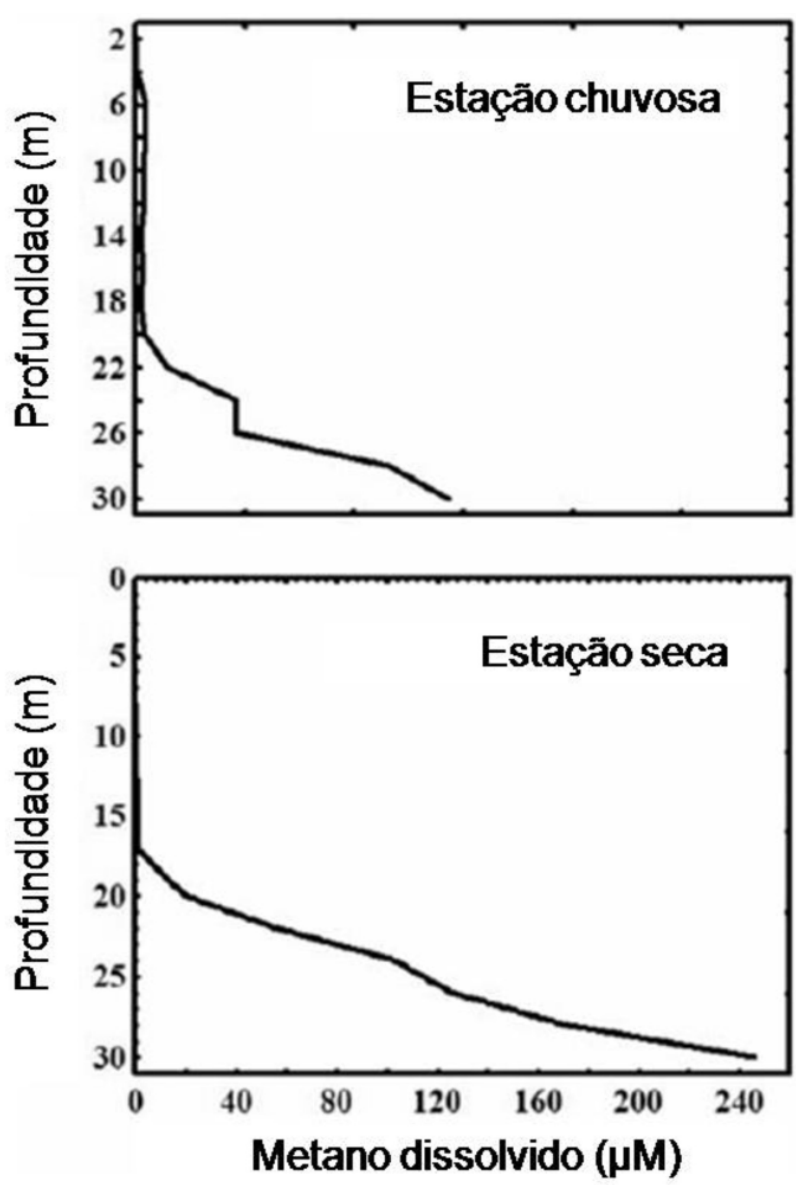

Figura 3. Concentração média de metano à montante da barragem de balbina (estação seca e estação chuvosa, respectivamente). Adaptado de Kemenes et al. 2007.

Figure 3. Average methane concentration on the Balbina dam upstream face during the rainy season(upper graph) and dry season (lower graph). Adapted from Kemenes et al. (2007). hidrelétricos. A primeira vai do estágio inicial de enchimento do reservatório até seus primeiros anos de existência ( $\sim 3$ a 5 anos), onde as emissões crescem rapidamente atingindo um pico em curto prazo e tendendo a decrescer ao longo dos anos. Esta fase corresponde à dominância da decomposição da biomassa pré-existente na área do reservatório sendo esta o principal componente da formação dos gases (Figura 5).

A segunda fase corresponde à dominância das emissões permanentes do reservatório. Nesta fase, as principais fontes dos gases é a biomassa formada no próprio reservatório, a que chega ao reservatório pelos seus tributários e uma pequena contribuição da biomassa residual. As Figuras 6 e 7 indicam uma diminuição das emissões ao longo do tempo. Este fenômeno é mais claro no caso do $\mathrm{CH}_{4}$ emitido por bolhas, excetuando o caso do reservatório de Três Marias.

Galy-Lacaux et al. (1999) também demonstraram tal padrão em resultados experimentais e simulações para o reservatório de Petit Saut na Guiana Francesa (Figura 8).

Resultados obtidos na região boreal indicam que as emissões de gases chegam ao seu valor máximo entre 3 a 5 anos após o enchimento do reservatório, decaindo para níveis praticados em ambientes aquáticos naturais em cerca de 10 anos para o $\mathrm{CO}_{2}$ e 4 anos para o $\mathrm{CH}_{4}$ (Tremblay et al. 2005). No caso das regiões semi-áridas e tropicais, o tempo para restauração dos

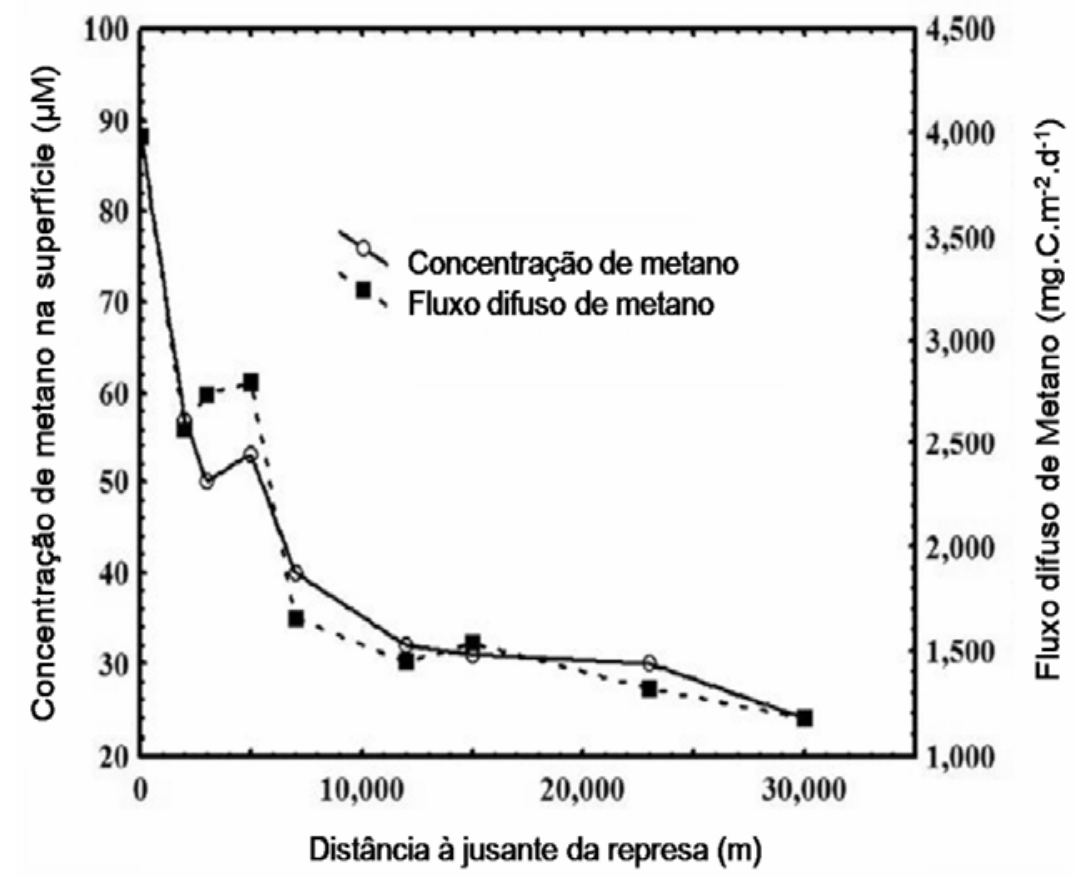

Figura 4. Concentração média de metano à jusante de Balbina. Extraído e modificado de Kemenes et al. (2007).

Figure 4. Average methane concentration on the Balbina dam downstream face. Extracted and modified from Kemenes et al. (2007). 
níveis ambientais deve ser mais longo tendo em vista a questão da temperatura, qualidade da água e outros fatores ambientais. Um exemplo é a grande contribuição de carbono alóctone que mantém os reservatórios em condições anóxicas e níveis significativos de emissões de $\mathrm{CH}_{4}$ (Tremblay et al. 2005).

Pode-se observar nas principais referências bibliográficas sobre o assunto (Santos et al. 2005) que: a) em termos gerais, as emissões de $\mathrm{CH}_{4}$ por bolhas decrescem com o tempo, admitindo-se um comportamento exponencial negativo destas emissões; b) para o $\mathrm{CO}_{2}$ emitido por bolhas, os valores de fluxo são baixos e bastante similares entre um período de tempo assumindo um comportamento de uma reta plana e c) a emissão de $\mathrm{CH}_{4}$ por difusão é muito irregular com picos de emissão em determinados períodos de tempo, não apresentando correlação com o tempo.

\section{A REPRESENTATIVIDADE DA AMOSTRA- GEM DOS RESERVATÓRIOS ESTUDADOS E A EXTRAPOLAÇÃO PARA OUTROS RESER- VATÓRIOS \\ A) EXTRAPOLAÇÃO ESPACIAL DO RESERVATÓRIO}

A emissão de cada uma das represas selecionadas foi determinada por amostragem em diversos pontos

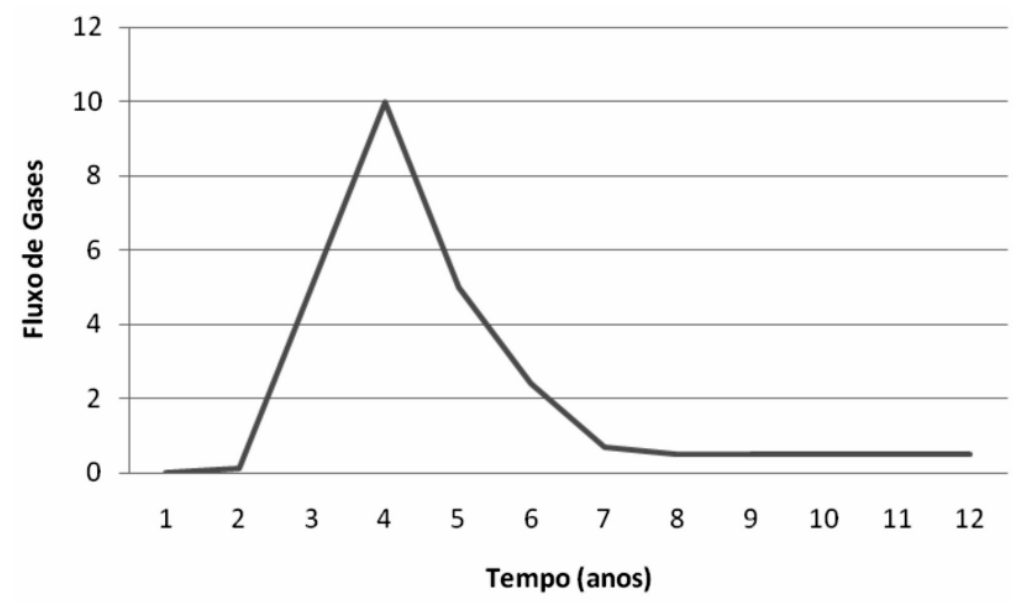

Figura 5. Modelo teórico de emissão de gases de reservatórios hidrelétricos.

Figure 5. Theoretical model of gas emissions in hydroelectric reservoirs.

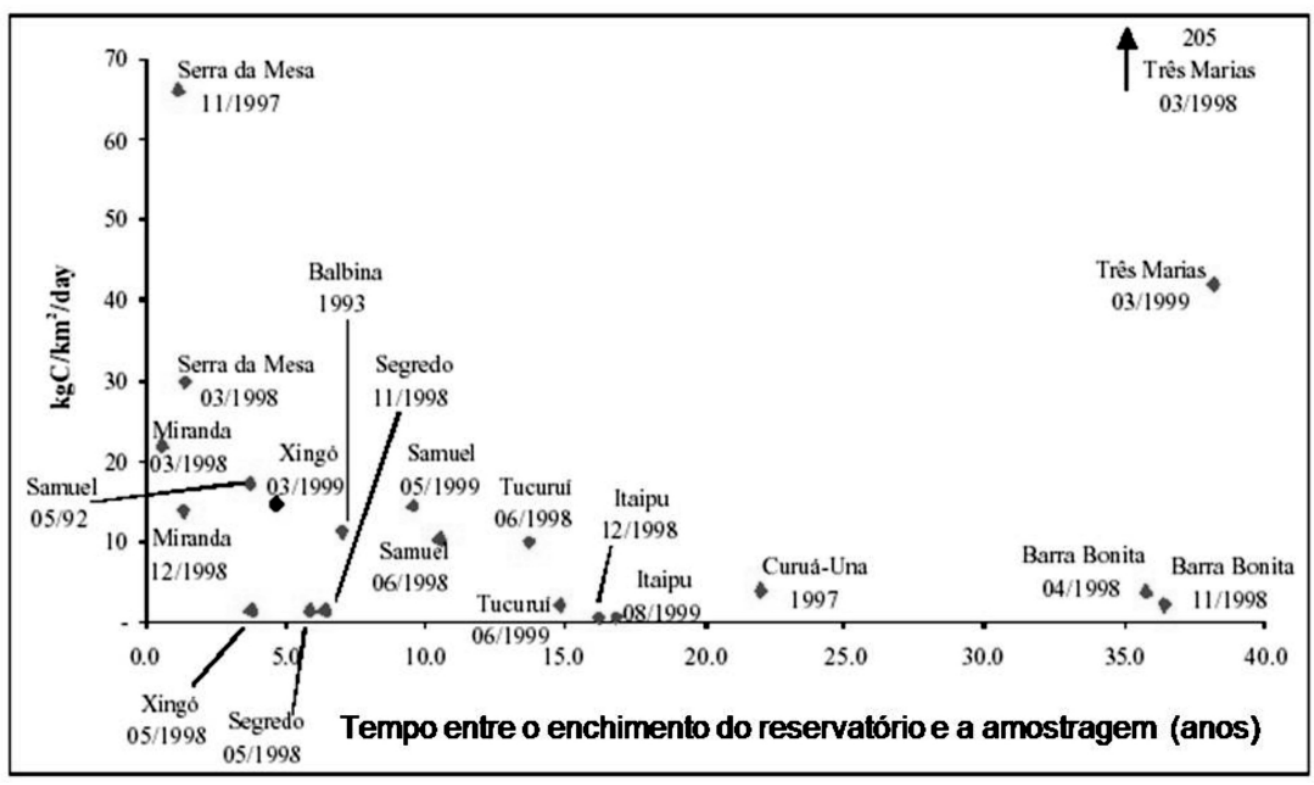

Figura 6. Emissões médias de $\mathrm{CH}_{4}$ através de bolhas em alguns reservatórios brasileiros. Figure 6. Mean methane emissions by bubbling in the studied Brazilian hydroelectric reservoirs. 


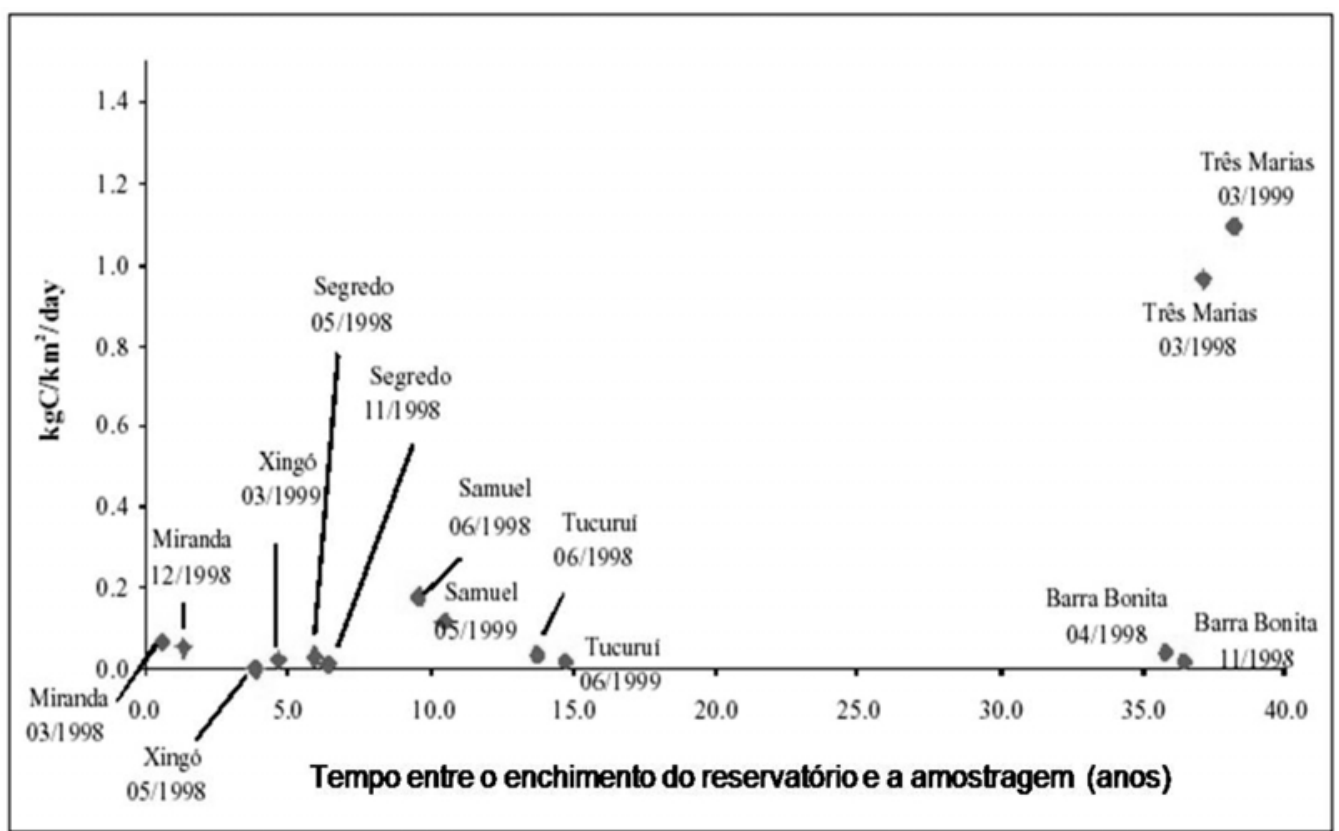

Figura 7. Emissões médias de $\mathrm{CO}_{2}$ através de bolhas em alguns reservatórios brasileiros.

Figure 7. Mean $\mathrm{CO} 2$ emissions by bubbling in the studied Brazilian hydroelectric reservoirs.

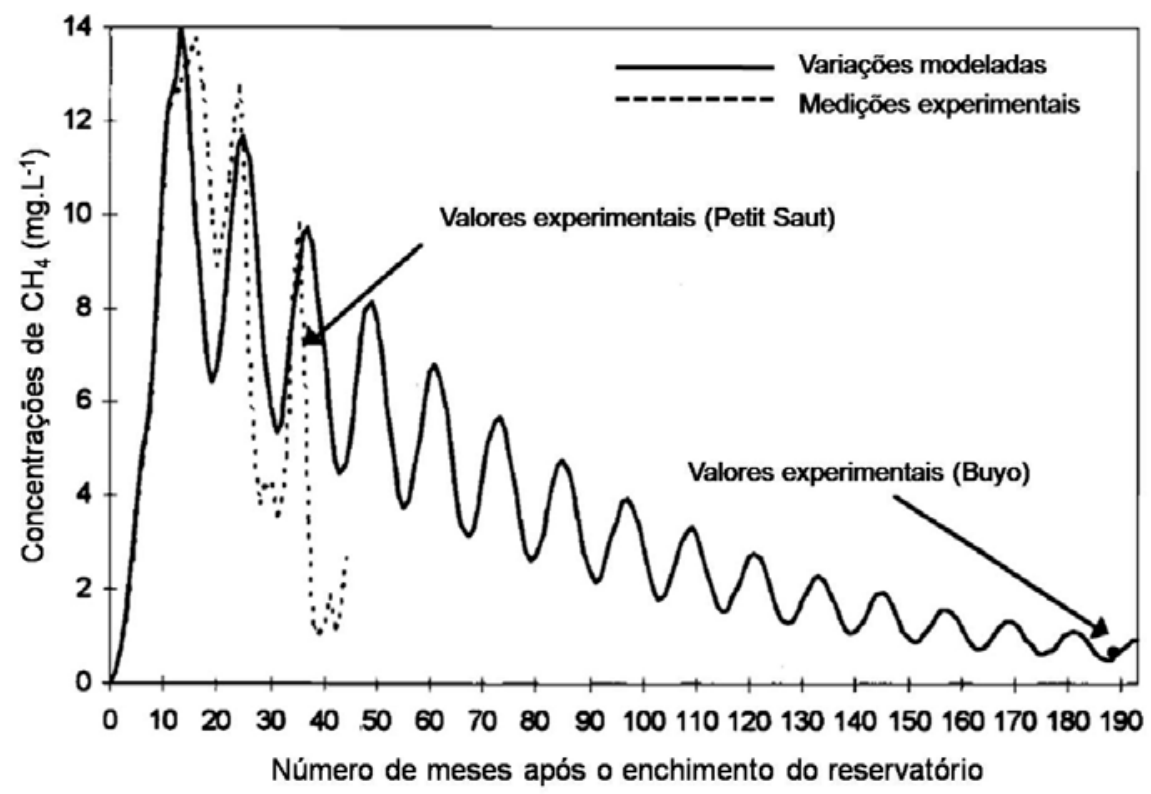

Figura 8. Concentração de metano $\left(\mathrm{CH}_{4}\right)$ dissolvido na água no reservatório de Petit Saut, Guiana Francesa. Extraído e modificado de Galy-Lacaux et al. (1999).

Figure 8. Dissolved methane concentrations in water samples from the hydroelectric reservoir of Petit Saut, French Guiana. Extracted and modified from Galy-Lacaux et al. (1999).

através da "extrapolação" dos resultados para obtenção de um valor válido para toda a represa. Observou-se anteriormente que havia forte dependência do tipo de ambiente com a taxa de emissão de $\mathrm{CH}_{4}$ por bolhas. Estes tipos de ambientes foram classificados como paliteiro, calha e ambiente ocupado por vegetação terrestre entre períodos anuais de inundação.
Incluindo dados de outros reservatórios, novas variáveis passaram a ser registradas como importantes no estabelecimento do regime de emissão: profundidade do local, tipo de vegetação inundada, idade do afogamento, temperatura da água, regime de ventos e intensidade da correnteza. Estas características complementam o critério anteriormente 
adotado, porém não o invalidam. Na medida em que a idade do afogamento aumenta, a profundidade do local tende a ser característica dominante na emissão ebulitiva dado o efeito da pressão hidrostática sobre a formação e eclosão das bolhas embora afete pouco a emanação, pois este fenômeno ocorre entre a mudança de fase água-ar, logo na superfície do reservatório.

Um dos fatores que parece ser preponderante na emissão de gases por reservatórios, são as faixas de profundidade. As baixas profundidades coincidem com as áreas periodicamente expostas e colonizadas por nova vegetação terrestre, e as maiores coincidem com as regiões de "calha". Resultados preliminares mostram que a dependência da profundidade é muito regular, mas há desvios decorrentes da idade e do tipo de vegetação inundada. O lado forte do critério da profundidade é a possibilidade de se obter dados precisos sobre que proporção do reservatório é situada em cada faixa de profundidade, eliminando com isto a necessidade do julgamento um tanto subjetivo de quanta área é ocupada por, digamos, paliteiros, calha, entre outros.

Já observamos (dados não publicados) que a difusão ocorre em todo espelho d'água de todos os reservatórios até hoje pesquisados e não constituem um grande problema para a extrapolação. Em termos gerais o emprego de média aritmética tem sido suficiente para a obtenção de um valor representativo para todo o reservatório. No entanto, a emissão de gases através de bolhas apresenta uma grande variação entre diferentes locais do reservatório. Pode-se concluir que as áreas devem ser bem escolhidas para este tipo de amostragem tendo em vista este caráter aleatório percebido. Em alguns locais, há uma forte produção de gás na forma de bolhas, principalmente em braços abrigados dos reservatórios onde a circulação de água é baixa e regiões de pouca profundidade. De maneira geral, ambientes com profundidades acima de $20 \mathrm{~m}$ inibem o desprendimento das bolhas devido à pressão hidrostática.

Recomenda-se o uso da extrapolação por faixas de profundidade (de forma ponderada) com o emprego de um modelo geométrico ou o emprego de um modelo matemático polinomial do tipo cota versus área ou em melhor caso o uso de um modelo digital do terreno a partir de dados batimétricos. A diferença marcante entre as emissões de $\mathrm{CH}_{4}$ por bolhas, que quase inexistem em áreas profundas (regiões da antiga calha do rio) e as altas taxas encontradas nas regiões rasas dos reservatórios, mostram claramente este padrão diferenciado de emissão nos reservatórios.

\section{B) EXTRAPOLAÇÃO ENTRE DIFERENTES RESER- VATÓRIOS}

Este é um dos maiores desafios a serem enfrentados utilizando dados obtidos em alguns pontos e em alguns dias do ano. O maior problema é obter um valor de emissões para cada reservatório e para o conjunto dos reservatórios existentes no país. Usamos duas aproximações diferentes, a primeira empírica, através da média ponderada de acordo com a distribuição da profundidade em cada reservatório, agrupada por latitude; e a segunda teórica, utilizando a média integrada para todos reservatórios, assumindo a distribuição de emissões dada por uma lei de potência.

A lei de potência utilizada é típica de fenômenos chamados de criticalidade auto organizada, geralmente com um perfil fractal da intensidade do fenômeno no tempo (citação). A lei de potência dá o número de eventos $\mathrm{N}$ por intensidade $\mathrm{I}$ (expressa no nosso caso em massa de carbono ou do gás emitida por unidade de área e de tempo).

$\mathrm{N}(\mathrm{I})=\mathrm{AI}^{-\lambda}$

As bases gerais desta teoria podem ser encontradas de forma compreensível no livro de Per Bak (1995) "How Nature Works - The Science of Self Organized Criticality". A idéia inicialmente exposta por este autor (Per Bak et al. 1987) é baseada em um modelo computacional do tipo autômato celular para simular o comportamento de uma pilha de areia sobre uma mesa sobre a qual se deixa cair continuamente areia. A certa altura, a pilha se estabiliza rejeitando o excesso de areia através de avalanchas, em geral pequenas, algumas maiores ou grandes e muito poucas catastróficas, quando a pilha desaba total ou parcialmente. A distribuição do inúmero $\mathrm{N}$ de desabamentos varia com a intensidade I elevada a uma potência negativa fixa, -b, como na expressão acima.

A lei de Richter, cujo nome batiza uma das escalas de medidas de terremotos, mostra que o número de abalos sísmicos em função da intensidade segue esta mesma lei. Embora algumas extrapolações conjectu- 
radas por Back sejam criticadas, há muitos casos em que ocorre a lei de potência como uma distribuição estatística quando perturbações muito pequenas ou fatores não controlados levam a efeitos pequenos ou grandes indiferentemente. Em geral este comportamento é associado à influência de áreas vizinhas no que ocorre em um sítio, como se verifica no autômato celular nas simulações em computador. Tais casos são verificados em deslizamentos de terra e na dinâmica de bacias hidrográficas.

Conjecturou-se ser cabível a aplicação da lei de potência no estudo estatístico das emissões de gases em hidrelétricas pelas seguintes razões:

a) As emissões medidas têm predominantemente baixa intensidade, algumas têm intensidade maior e poucas têm grande intensidade em termos de massa de carbono por área na unidade de tempo (t.C.m ${ }^{-2} \cdot$ ano $^{-1}$ ).

b) Observamos grandes variações da intensidade das emissões em mesmo local e de um local para outro no mesmo tempo e em cada local da barragem ao longo do tempo, delineando um perfil fractal.

c) Há coexistência de vários fatores que influenciam a emissão no lago, desde o tempo de fechamento da barragem ou idade da represa, a vida e os processos no lago, o carbono trazido da bacia hidrográfica pela água, bombeado da atmosfera ou retirado do solo, a profundidade, a presença de oxigênio, a formação de camada anaeróbica no fundo, o regime hidrológico sazonal, a temperatura, o vento, a vazão. Portanto torna-se difícil o controle para estabelecer uma relação causal e ao elegermos algum fator entre tantos estamos sujeitos a uma grande incerteza.

d) A dificuldade de se realizar as medições experimentais in loco, para acumular dados e obter uma boa estatística para cada barragem e para o conjunto delas, nos motivam a utilizar alguma técnica automática de medição.

Portanto, buscamos dar um tratamento estatístico usando uma hipótese teórica, a da lei de potência, além da média ponderada, empiricamente, por profundidade e extrapolada por latitude para o conjunto das hidrelétricas. Testamos duas distribuições do número de eventos por intensidade: I) a distribuição da lei de potência acima definida e II) a distribuição com decaimento exponencial.

Obtivemos um bom coeficiente de correlação (cerca de 0,8$)$ na primeira destas hipóteses, melhor do que na segunda delas, que se revelou sofrível e foi abandonada em favor da distribuição da lei de potência. A distribuição com decaimento exponencial do número de emissões com o crescimento da intensidade significaria que cada emissão seria um evento independente, enquanto a lei de potência admite a influência da vizinhança e, através dela, de regiões distantes dentro do lago. Esta última, além de ter permitido melhor ajuste entre curva teórica e dados, é a mais adequada interpretação do processo de emissão.

Os dados medidos foram agrupados em quatro classes combinando dois gases $\left(\mathrm{CO}_{2}\right.$ e $\left.\mathrm{CH}_{4}\right)$ e dois processos de emissão (ebulição e difusão). Os resultados obtidos para as taxas de emissão de $\mathrm{CO}_{2}$ por ebulição e difusão foram intermediários e maiores, respectivamente enquanto que para as taxas de emissão de $\mathrm{CH}_{4}$ por ebulição e difusão foram menores e muito pequenos, respectivamente.

A média de todos os reservatórios foi calculada usando a lei de potência, a partir de uma integral entre limites dados pelos valores máximo e mínimo, obtendo um resultado que é proporcional à subtração de potências negativas destes valores.

Como um deles é muito maior que o outro, pode-se desprezar o termo contendo o valor máximo, ficando o valor médio dependente apenas do mínimo. Se esta hipótese for verdadeira, a emissão média teórica calculada pela lei de potência é menor do que pela média aritmética sobre o conjunto de dados acumulados, ou mesmo pela média ponderada pela profundidade (Rosa et al. 1996).

Para o cálculo da extrapolação, empregando-se este critério, foram agregados os dados de todos os reservatórios em tipo de gás $\left(\mathrm{CH}_{4}\right.$ e $\left.\mathrm{CO}_{2}\right)$ por dois tipos de processos de transporte (ebulição e emanação). Procedeu-se de tal forma, pois a acumulação de dados por cada tipo de reservatório mostrou-se insuficiente para uma análise significativa do ponto de vista estatístico.

Em seguida, criamos intervalos de classe para cada tipo de gás combinado com tipo de processo e procedemos à construção de gráficos de histogramas de forma a representar a relação entre a intensidade (emissão) e a freqüência (número de vezes que o dado se enquadrou no intervalo selecionado).

Neste caso, para construir os histogramas utilizou-se o valor médio de cada intervalo de classe como sendo o valor representativo. Após esta etapa, procedemos a um 
ajuste estatístico dos valores, como forma de se obter um padrão compatível com os pressupostos da teoria da lei da potência, ou seja, que os valores de freqüência dos dados obtidos deveriam decair na medida em que se aumentava a intensidade do fenômeno.

\section{AS EMISSÕES LÍQUIDAS DOS RESERVATÓ- RIOS DE HIDRELÉTRICAS}

Uma importante questão, muitas vezes desconsiderada, se refere às emissões naturais anteriores à construção da barragem. Estas devem ser descontadas das emissões futuras atribuídas ao reservatório. A literatura científica sobre o assunto denomina estas emissões como líquidas. O conhecimento atual sobre como os reservatórios hidrelétricos se comportam como um sistema ambiental integrado e como seus vários ecossistemas respondem à intervenção antropogênica é incompleto.

Não obstante, existem alguns estudos quantitativos dos efeitos ambientais de grande escala resultantes do alagamento de áreas florestadas que simplesmente extrapolam os resultados de estudos de um único ou de poucos pontos para todo o reservatório, com pouca consideração de suas diferentes zonas ecológicas, hidrológicas e climáticas.

Realizamos um estudo desta natureza ao avaliar a emissão de GEE de áreas naturais que seriam inundadas para a construção do Complexo Hidrelétrico (CHE) de Belo Monte. No decorrer do estudo foram realizadas duas campanhas de coleta de dados em campo: a primeira ocorreu no período de 27 a 31 de outubro de 2003 (estação seca) e a segunda de 10 a 14 de maio de 2004 (estação chuvosa).

As campanhas consistiram basicamente em tomadas de medidas de fluxos de gases na interface água-atmosfera; medidas de concentração de carbono orgânico dissolvido, particulado e total na água; medidas de concentração de $\mathrm{CH}_{4}$ na água; parâmetros físicos e químicos da água; perfil de temperatura na camada sob e sobre a lâmina d'água; taxa de sedimentação de carbono no sedimento de fundo e medidas dos gases $\mathrm{CH}_{4}, \mathrm{CO}_{2} \mathrm{e}$ $\mathrm{N}_{2} \mathrm{O}$ em solos próximos à área do reservatório.

Este estudo teve como objetivo principal instituir um programa de monitoramento das emissões de gases de efeito estufa (GEE), provenientes da fase rio e na área terrestre que fará parte da área a ser inundada pelo CHE de Belo Monte. As medidas de parâmetros físico- químicos da água e das concentrações de $\mathrm{CH}_{4}$ na coluna d'água possibilitarão desenvolver um modelo do ciclo do carbono de forma a avaliar a participação de diversas fontes de GEE na fase rio e descontar estes dados das emissões do futuro reservatório de Belo Monte.

A área a ser inundada foi considerada para a avaliação de entrada e saída de carbono, e foi tratada como uma caixa, ou seja, um compartimento espacial tridimensional com extensão da área a ser alagada, recebendo carbono e entregando carbono.

\section{As entradas de carbono consideradas foram:}

(1) Carbono do $\mathrm{CO}_{2}$ do ar quando consumido pela fotossíntese das plantas (Produção Primária Líquida - NPP);

(2) Carbono do $\mathrm{CO}_{2}$ absorvido pela água do rio ou dos alagados;

(3) Carbono, dissolvido ou particulado, trazido pelo rio;

(4) Carbono absorvido como $\mathrm{CH}_{4}$ ou $\mathrm{CO}_{2}$ pelo solo que será inundado;

(5) Carbono trazido pela água do subsolo.

As saídas de carbono consideradas foram:

(1) Carbono do $\mathrm{CO}_{2}$ emitido pelas raízes e bactérias heterotróficas em sua respiração. Essa parcela já será subtraída da absorção de modo que seja contada apenas a produção primária líquida (NPP) no item "entrada de carbono do $\mathrm{CO}_{2}$ do ar";

(2) Carbono contido nos gases emitidos pelas superfícies de água, do rio e dos alagados;

(3) Carbono dissolvido ou particulado entregue à jusante pelo compartimento considerado;

(4) Carbono que sai da "caixa" e acumula no solo.

Foram estimadas, independentemente umas das outras, todas as entradas e saídas do compartimento. Foi também estimada a variação do carbono residente na caixa. Essa variação de carbono é dada na literatura atual como sendo um pequeno aumento de carbono residente. Tal parcela foi levada em conta como uma saída.

Para a obtenção dos resultados apresentados na Tabela I avaliou-se a entrada e a saída de carbono do balanço da primeira campanha, com entrada e saída da segunda campanha. Nota-se aumento por um fator de 3,1 no trânsito de carbono pela "caixa preta" do balanço. O fator 3,1 é resultado da divisão (12.117/3.894) entre as médias para ambas as campanhas, de entrada mais saída de carbono. 
Tabela I. Comparação entre valores de fluxo de carbono (C) nas duas campanhas ( $1^{\mathrm{a}}$ campanha de 27 a 31 de outubro de 2003 e $2^{\mathrm{a}}$ de 10 a 14 de maio de 2004).

Table I. Comparison between the carbon flow values obtained in the two sampling campaigns: 27 to 31 October, 2003 and 10 to 14 May, 2004.

\begin{tabular}{cccc}
\hline $\begin{array}{c}\text { Balanço de } \\
\text { Carbono }\end{array}$ & $\begin{array}{c}\text { Entrada } \\
\text { t C.d }^{-1}\end{array}$ & $\begin{array}{c}\text { Saída } \\
\text { t C.d }^{-1}\end{array}$ & $\begin{array}{c}\text { Média } \\
\text { t C.d }^{-1}\end{array}$ \\
\hline $1^{\mathrm{a}}$ campanha & $4.172 \pm 314$ & $3.615 \pm 305$ & $3.894 \pm 438$ \\
$2^{\mathrm{a}}$ campanha & $12.350 \pm 942$ & $11.883 \pm 977$ & $12.117 \pm 1.357$ \\
\hline
\end{tabular}

É possível que o aumento do carbono circulante seja sazonal e nossa equipe tenha detectado uma amostra dessa sazonalidade.

Os balanços acima revelam que as principais parcelas de entrada e saída de carbono são as trazidas e levadas pelo próprio rio, com cerca de $90 \%$ de participação neste balanço.

Durante o período seco ( $1^{\mathrm{a}}$ campanha), a segunda entrada mais importante de carbono ocorreu através da produção primária $(16,6 \%)$. A segunda saída mais relevante $(6,1 \%)$ ocorreu através da emissão do solo. A saída de carbono na forma de emissão pela superfície da água é insignificante $(0,1 \%)$ no período seco.

Já no período de chuvas ( $2^{\mathrm{a}}$ campanha), a segunda entrada mais importante $(7 \%)$ de carbono ocorreu através da água do subsolo, e a segunda saída mais significativa $(5,5 \%)$ ocorreu através da emissão pela superfície da água.

Os fluxos de gases de efeito estufa obtidos neste estudo são apresentado na Tabela II.

\section{CONSIDERAÇÕES FINAIS}

Através das comparações realizadas entre os reservatórios estudados, chegou-se a conclusão de que há uma grande variação entre os dados de emissão de GEE, o que indica a necessidade de um cuidado maior na escolha de futuros projetos pelo setor elétrico brasileiro. Esta variação faz com que à eficiência das hidrelétricas em comparação com tecnologias termelétricas equivalentes também seja variável. A variação dos valores de emissão dos gases inter e intra-reservatórios podem ser atribuídos a distintos regimes de circulação de águas, que proporcionam condições diferenciadas de qualidade de água e geração de matéria orgânica.

Em alguns reservatórios notou-se que o regime de operação também pode influenciar na emissão dos gases. Com a intensa geração de energia o reservatório depleciona-se de forma rápida, criando a possibilidade de que nos braços dendríticos rasos (onde o fundo é exposto periodicamente à colonização por vegetação terrestre), ocorra intensa metanogênese devido ao decaimento desta vegetação após sua inundação que ocorre com a subida do nível da água na estação chuvosa. Emissões podem variar de acordo com a profundidade e com a distribuição da biomassa submersa. As emissões de gases também variam ao longo do tempo, com elevadas taxas durante um curto período de tempo que ocorre logo após submersão. A taxa de emissão de gases após este curto período ainda é desconhecida.

Tabela II. Fluxos difusivos e ebulitivos de gases na superfície e na coluna d'água e fluxos difusivos na área terrestre em futura área do Complexo Hidrelétrico Belo Monte. Dados para estação seca obtidos de 27 a 31/10/2003 e para a estação úmida de 10 a 14/05/2004. (Média \pm Desvio padrão em mg. $\mathrm{m}^{-2} \cdot \mathrm{d}^{-1} ; \mathrm{n}=$ número amostral; $\mathrm{nd}=$ não determinado).

Table II. Diffusion and ebullition gas fluxes on the water surface and column, and land diffusive fluxes at the prospective hydroelectric reservoir area of Belo Monte. Data on dry season obtained in 27 to 31 October, 2003 and on wet season in 10 to 14 May, 2004. (nd= not determined).

\begin{tabular}{clc}
\hline $\begin{array}{c}\text { Fluxos } \\
\text { (Difusão água-ar) }\end{array}$ & \multicolumn{1}{c}{ Estação seca } & \multicolumn{1}{c}{ Estação úmida } \\
\hline & FLUXO DIFUSIVO NA SUPERFICIE D’ÁGUA \\
\hline $\mathrm{CH}_{4}$ & $9,63 \pm 6,15(\mathrm{n}=20)$ & $23,59 \pm 15(\mathrm{n}=24)$ \\
$\mathrm{CO}_{2}$ & $-68,8 \pm 1328(\mathrm{n}=20)$ & $6617 \pm 4526(\mathrm{n}=24)$ \\
$\mathrm{N}_{2} \mathrm{O}$ & $-0,458 \pm 1,95(\mathrm{n}=20)$ & $0,025 \pm 0,499(\mathrm{n}=24)$ \\
\hline \multicolumn{4}{c}{ FLUXO EBULITIVO DA COLUNA D'ÁGUA } \\
\hline $\mathrm{CH}_{4}$ & $3,14 \pm 10,92(\mathrm{n}=11)$ & $64,91 \pm 133,92(\mathrm{n}=12)$ \\
$\mathrm{CO}_{2}$ & $0,21 \pm 0,64(\mathrm{n}=11)$ & $2,04 \pm 3,27(\mathrm{n}=12)$ \\
$\mathrm{N}_{2} \mathrm{O}$ & nd & $0,351 \pm 0,5(\mathrm{n}=12)$ \\
\hline \multicolumn{4}{c}{ FLUXO DIFUSIVO EM ÁREA TERRESTRE } \\
\hline $\mathrm{CH}_{4}$ & $1,89.10^{-6} \pm 4,58.10^{-6}(\mathrm{n}=11)$ & $\mathrm{nd}$ \\
$\mathrm{CO}_{2}$ & $2,83.10^{-3} \pm 3,42.10^{-3}(\mathrm{n}=11)$ & nd \\
$\mathrm{N}_{2} \mathrm{O}$ & $-1,46.10^{-7} \pm 0,03.10^{-7}(\mathrm{n}=11)$ & nd \\
\hline \multicolumn{4}{c}{}
\end{tabular}


Muitos ambientes naturais emitem $\mathrm{CH}_{4}$, especialmente pântanos e outras áreas úmidas ou habitats de florestas em climas tropicais. Estas emissões deveriam ser consideradas e descontadas em cálculos de emissões futuras de $\mathrm{CH}_{4}$ quando um reservatório inunda este tipo de ambiente. Este método garante que os dados obtidos após a inundação representam realmente o aumento na emissão de $\mathrm{CH}_{4}$ provocado pela inundação da área pela represa.

A emissão de $\mathrm{CH}_{4}$ pelas hidrelétricas é sempre desfavorável para a hidreletricidade, pois mesmo que o carbono origine-se de fontes naturais, ele se torna um gás de maior Potencial de Aquecimento Global (Global Warming Potential - GWP) no computo final. Já a emissão de $\mathrm{CO}_{2}$ em parte pode ser originada da atmosfera e ser incorporada ao sistema do reservatório pela ciclagem natural do carbono em ciclo curto de tempo.

\section{REFERÊNCIAS BIBLIOGRÁFICAS}

BAK, P. 1995. How Nature Works - The Science of Self Organized Criticality..Springer-Verlag, 212p.

FEARNSIDE, P.M. 1995. Hydroelectric Dams in the Brazilian Amazon Significant Sources of Greenhouse Gases, Environmental Conservation, 22: 7-19.

FEARNSIDE, P.M. 1996. Hydroelectric Dams in Brazilian Amazonia: Response to Rosa, Schaeffer and Santos, Environmental Conservation, 23:2-2.

FEARNSIDE, P.M. 2004. Greenhouse Gas Emissions from Hydroelectric Dams: Controversies Provide a Springboard for Rethinking a Supposedly 'Clean' Energy Source. An Editorial Comment, Climate Change, 66: 1-8.

GALY-LACAUX, C.; DELMAS, R.; KOUADIO, J.; RICHARD, S. \& GOSSE, P. 1999. Long-term Greenhouse Gas Emissions from Hydroelectric Reservoirs in Tropical Forest Regions, Global Biogeochemical Cycles, 13: 503-517.

IPCC. 2001. Climate Change 2001. Synthesis Report, Cambridge University Press, London.

RICHEY, J.E.; DEVOL, A.H.; WOFSY, S.C.; VICTORIA R. \& RIBEIRO, M.N.G. 1988. Biogenic gases and the oxidation and reduction of carbon in the Amazon River and floodplain waters. Limnology and Oceanograpy, 33:551-561.

KEMENES, A. 2006. Estimativa das Emissões de gases de efeito estufa $\left(\mathrm{CO}_{2}\right.$ e $\left.\mathrm{CH}_{4}\right)$ pela hidrelétrica de Balbina, Amazonia Central, Brasil. INPE, Universidade Federal do Amazonas, Tese de doutorado, $95 \mathrm{p}$.

KEMENES, A.; FORSBERG, B.R. \& MELACK J.M.
2007. Methane release below a tropical hydroelectric dam, Geophysical Research Letters, 34, L12809, doi:10.1029/2007GL029479.

SANTOS, M. A. 2000. Inventário de Emissões de Gases de Efeito Estufa Derivadas de Hidrelétricas. Rio de Janeiro, Tese de Doutorado, PPE/COPPE/UFRJ, 147 p.

SANTOS, M.A.; MATVIENKO, B.; ROSA, L.P.; SIKAR, E.; SANTOS, E.O. 2005. Gross Greenhouse Gas Emissions from Braziliam Hydro Reservoir. In: Alain Trembaly; Louis Varfalvy; Charlotte Roehm; Michele Garneau. (Org.). Greenhouse Gas Emissions - Fluxes and Processes - Hydroelectric Reservoirs and Natural Environments. Springer-Verlag, 267-291.

ROSA, L.P.; SCHAEFFER, R. \& SANTOS, M.A. 1996 Are

Hydroelectric Dams in the Brazilian Amazon Significant

Sources of Greenhouse Gases. Environmental Conservation 66: 2-6.

ROSA, L.P; SANTOS, M.A.; TUNDISI, J.G. \& SIKAR, B.M. 1997. Measurements of Greenhouse Gas Emission at the Samuel, Tucuruí and Balbina Dams, Brazil, In: Hydro-power Plants and Greenhouse Gas Emissions, Rosa, L.P. \& Santos, M.A. (eds), COPPE publication, Rio de Janeiro.

ROSA, L.P.; SANTOS, M.A.; MATVIENKO, B.; SANTOS, E.O. \& SIKAR, E. 2004. Greenhouse Gas Emissions from Hydroelectric Reservoirs in Tropical Regions, Climatic Change 66: 9-21.

ROSA, L.P.; SANTOS, M.A.; MATVIENKO, B.; SIKAR, E.; SANTOS, E.O. 2006. Scientific Errors in the Fearnside Comments on Greenhouse Gas Emissions (GHG) from Hydroelectric Dams and Response to His Political Claiming. Climatic Change, 75: 498-510.

TREMBLAY, A.; VARVALVY, L.; ROHEM, C. \& GARNEAIR, M. 2005. Greenhouse Gas Emissions - Fluxes and Process, Hydroelectric Reservoir and Natural Environments, Springer.

Submetido em 01 de agosto de 2008. Aceito em 23 de agosto de 2008. 